\title{
A DESCRIPTIVE STUDY TO ASSESS THE KNOWLEDGE AND PRACTICE REGARDING MENSTRUAL HYGIENE AMONG THE GIRL STUDENTS AT SELECTED COLLEGES OF GHAZIABAD (UP)
}

\author{
Ms. Manju Rajput' ${ }^{1}$ Ms. Anjum Abbasi ${ }^{2}$, Ms. G. Manjulavathi ${ }^{3}$ \\ Vice Principal, School of Nursing, Noida International University, Greater Noida (UP)' \\ Assistant Professor, Galgotias University, Greater Noida (UP)² \\ Professor, Santosh Nursing College, Ghaziabad (UP)³
}

\begin{abstract}
Statement: A descriptive study to assess the knowledge and practice regarding menstrual hygiene among the girl students at selected colleges of Ghaziabad (UP)Objectives: To assess the knowledge of girl students regarding menstrual hygiene. To determine the knowledge and practice regarding menstrual hygiene among girl students according to their demographic variables. To find out the association between selected demographic variables of girl students with their knowledge and practice.Methodology: Descriptive approach was used with non-experimental research design. Population was 30 girl students at Santosh Nursing college, Ghaziabad (UP)Purposive sampling technique was used for data collection. Result: In the present study $70 \%$ students were having good knowledge, $20 \%$ and $10 \%$ were having average to poor knowledge.
\end{abstract}

Keywords: Descriptive study, knowledge, menstrual hygiene, girl students 
"How long is a girl, a child? She is child, and then one morning you wake up she's a woman and dozen different people of whom you recognize none". Lovise Lamour.

A baby girl is said to have grown when there is an increase in physical size of her body. In the process of development there is a step by step process by which infants and children acquire variety of skill and functions. As they learn skills and gain from observing their surroundings, they become more and more mature. An increase in functionality of various body systems exhibiting different development skill is known as Maturation. During the process of development and maturation, the time period related to adolescence is a very crucial time in the life of a girl. Adolescence is usually a duration between the age of 11 and 20 years, during this period a significant transition is observed from childhood to adulthood. During the time period of adolescence, a girl experiences significant and perceptible changes in - physical appearance, cognitive, psychosocial and psychosexual domain. During this age significant developments of secondary sexual characteristics are seen among girls, and they experience development of a natural interest in the opposite sex. This part of the teen age is the crucial time when a girl is in the need of guidance and strong support of parents and experts such as nurses to experience an healthy lifestyles and rational approach for maintaining balanced behavior. Girls, generally enters puberty at 9 to 10 years of age, which is a bit earlier in comparison to boys who experience this at the age of $10-11$ years of age. Menstruations in girls commonly commences between the age of 9-15 years. During this time a lot of confusion and questions may come in the mind of a girl, and all of them must be answered rationally and logically. Thus, adolescence is the time that presents unique and challenging situations for nurse and it will represent different levels of vital identity information.

In a women's reproductive life, menstruation is a normal uterine function. This involves a monthly uterine bleeding for 4-5 days on regular basis, every 28 days from puberty to menopause. Bleeding commences from estrogen- progesterone primed endometrium, it outflows through vagina onto vulva. For every woman, cycle of menstruation is unique and individual. In her reproductive life, a woman experiences around 400 menses in all and about 13 menses in a year. In India, the age of menarche $h$ as been generally estimated to be between 10-16 years with an average of 13.5 years. During the time of menses in particular, personal hygiene becomes very important. Factors like washing, oral care, hair care, wound care, 
cleansing of personal utensils, along with the menstrual hygiene must be attended to very meticulously as it play a significant role in preventing infections. Personal hygiene being personal is guided by their own traditions, customs and specific instruction narrated by elders in the family. Menstruation is a phenomenon that is uniquely associated with the females, hence it demands a significant level of awareness among them. . The girls should be educated and made aware about the significance of menstruation and development of secondary sexual characteristics. It is very important that they must know about the selection of a secondary menstrual absorbent and its proper disposal. Electronic and print media can play crucial role by way of educational television programmes, talk shows, informative articles. Medical staff can arrange informative interaction programs in school, compulsory sex education in curriculum. The role of parents in this scenario cannot be ignored, with the help of their guidance and sharing their experience with the girl, it can be ensured that girls do not develop psychological upset, and the received education would also wipe away the age-old wrong ideas. Such deliberation will definitely make her feel free to discuss menstrual matters without any inhibitions and hesitations.

\section{Problem statement:}

A descriptive study to assess the knowledge and practice regarding menstrual hygiene among the girl students at selected nursing colleges of Ghaziabad (UP)

\section{Objectives:}

To assess the awareness and understanding of girl students regarding menstrual hygiene\& cleanliness.

To determine the knowledge and practice regarding menstrual hygiene among girl students according to their demographic variables.

To find out the association between selected demographic variables of girl students with their knowledge and practice.

\section{Inclusion criteria:}

Girl students of GNM batch-

- Who are willing to part in the study.

- Who are available during data collection.

- Who are able to read and speak English and Hindi.

- Who are studying in Santosh nursing college.

\section{Exclusion criteria:}

- B.Sc. Nursing girl students.

- Those who do not want to participate in study.

- Those who are not available during data collection.

- Those who are unable to read and speak English and hindi.

- Those who are not studying in Santosh nursing college.

\section{Description of Tool:}

Structured closed ended questionnaire method was prepared to assess understanding and practice.

The tool consists of different parts-

Part A- Demographic data consisting of 08 questions.

Part B- Knowledge questionnaire consisting of 10 questions. 
Part C- practice questionnaire consisting of 10 questions.

\section{Results-}

Part A- demographic data of girl students-
Section I- Frequency and percentage distribution of girl students according to their sociodemographic variables-

Table -1

$\mathbf{N}=\mathbf{3 0}$

\begin{tabular}{|c|c|c|c|}
\hline \multicolumn{2}{|l|}{ Socio-demographic Profile } & Frequency & Percentage (\%) \\
\hline \multirow{3}{*}{ Age in Years } & $17-20$ years & 14 & 46.7 \\
\hline & $21-24$ years & 14 & 46.7 \\
\hline & 25 years and more & 2 & 6.7 \\
\hline \multirow[b]{2}{*}{ Course of study } & GNM $1^{\text {st }}$ year & 15 & 50 \\
\hline & GNM $2^{\text {nd }}$ year & 15 & 50 \\
\hline \multirow{4}{*}{ Religion } & Hindu & 19 & 63.4 \\
\hline & Muslim & 6 & 20.0 \\
\hline & Christian & 5 & 16.6 \\
\hline & Others & 0 & 0 \\
\hline \multirow[t]{3}{*}{ Marital status } & Married & 4 & 13.3 \\
\hline & Unmarried & 26 & 86.6 \\
\hline & Widow & & \\
\hline \multirow[t]{3}{*}{ Type of family } & Nuclear & 6 & 20 \\
\hline & Joint & 21 & 70 \\
\hline & Extended & 3 & 10 \\
\hline \multirow[t]{4}{*}{ Educational Qualification } & Secondary & 11 & 36.7 \\
\hline & Higher secondary & 9 & 30 \\
\hline & Graduate & 7 & 23.2 \\
\hline & Post graduate & 3 & 10 \\
\hline \multirow{4}{*}{ Monthly family income/ month } & Rs 3000-6000 & 3 & 10 \\
\hline & Rs. 6001-9000 & 7 & 23.3 \\
\hline & Rs. $9001-12000$ & 7 & 23.3 \\
\hline & Rs. 12000 \& above & 13 & 43.4 \\
\hline \multirow[t]{2}{*}{ Dietary habits } & Vegetarian & 18 & 60 \\
\hline & Non- vegetarian & 12 & 40 \\
\hline
\end{tabular}


Section II: Frequency and percentage distribution of knowledge level of girl students about menstrual hygiene-

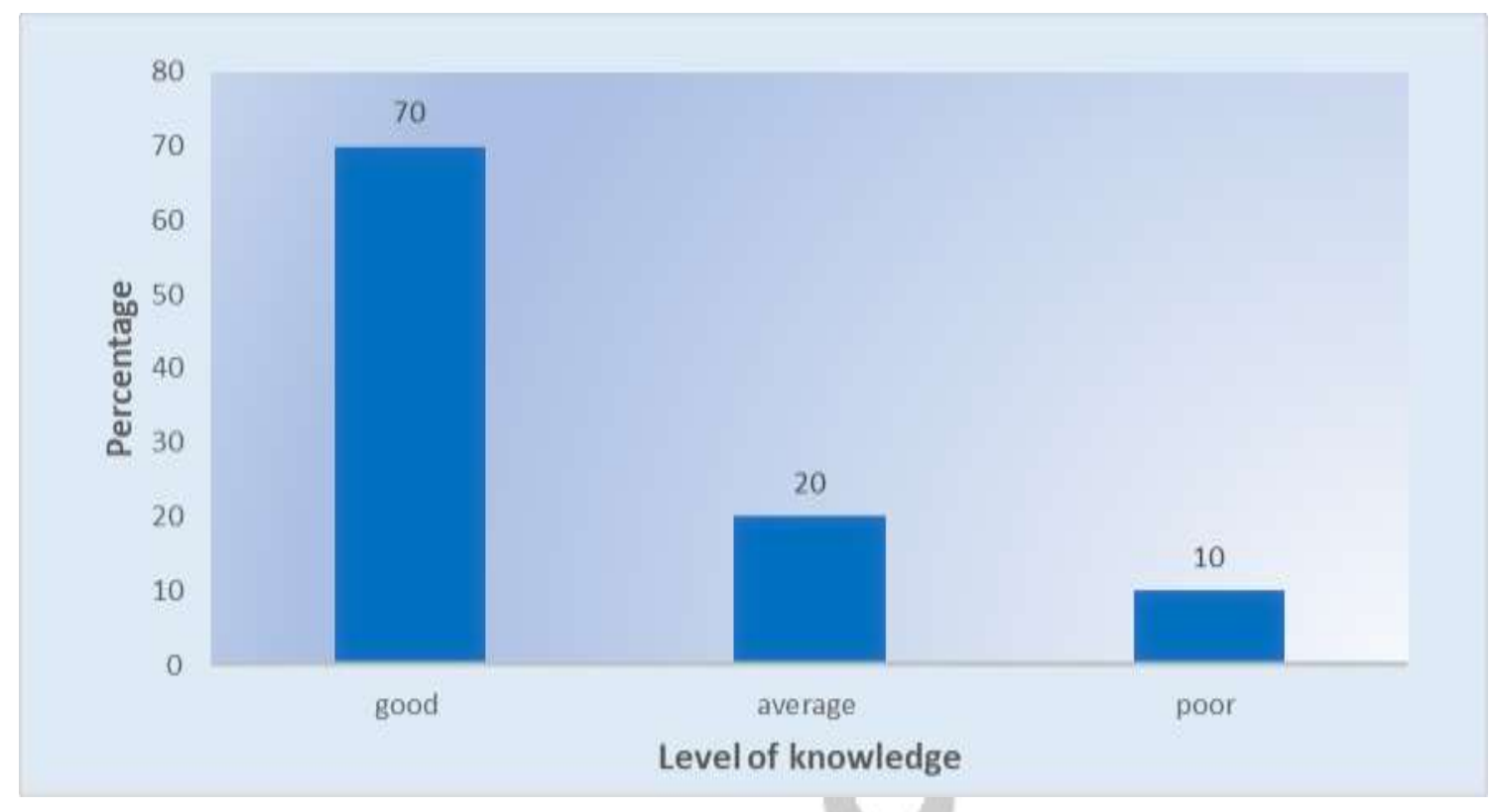

\section{Figure-1}

Above mentioned $70 \%$ were having good knowledge, $20 \%$ and $10 \%$ had average and poor knowledge, respectively.

Section III: Mean, median and standard deviation of knowledge of girl students-

\section{Table-2}

\begin{tabular}{|c|c|c|c|}
\hline Variables & Mean & Median & SD \\
\hline Knowledge & 50.9 & 52 & \pm 2.18 \\
\hline
\end{tabular}




\section{Table:3}

Section IV: Association between demographic variable of girl students and their knowledge score-

\begin{tabular}{|c|c|c|c|c|}
\hline Demographic variable & $\begin{array}{c}\text { Degree of } \\
\text { freedom }\end{array}$ & Chi square & P. value & Level of significance \\
\hline 1. Age & 4 & 20.56 & 0.048 & significant \\
\hline 2. Course of study & 5 & 14.60 & 0.002 & significant \\
\hline 3. Religion & 3 & 1.3 & 0.72 & Non-significant \\
\hline 4. Marital status & 6 & 2.47 & 0.95 & Non-significant \\
\hline 5. Type of family & 2 & 8.53 & 0.003 & Non-significant \\
\hline 6. Education status & 4 & 12.33 & 0.005 & Significant \\
\hline 7. Monthly family income & 5 & 5.80 & 0.96 & Non-significant \\
\hline 8. Dietary habits & 2 & 8.53 & 0.003 & Non-significant \\
\hline
\end{tabular}

Table 3 depicts the association between demographic variables and knowledge score. It is found that the demographic variables (age, course of study and educational qualification) are significant to the knowledge score of girl students of GNM.

\section{Implication:}

The findings of the study have implication not only related to the field of nursing but also other allied areas. In health care team nurse plays a vital role in providing health education to the target group of society. The researcher has the knowledge of the menstrual hygiene in females. Therefore, this study has an important implications in :

1. Nursing education

2. Nursing Practice:
3. Nursing research

4. Nursing administration

\section{Nursing Education:}

With more and more priority according to the health of the adolescent females. The primary task is to help the nurse to masters the fundamental level of understanding and update content for future. The result of the study enables the nurse to prepare themselves to provide the health \& hygeine education more effectively based 
on cultural and social background of adolescent girls. The proper dissemination of information regarding menstrual hygiene is essential to help adolescent girls by utilization of services available.

\section{Nursing Practice:}

Hospital nurses can utilize the findings of the present study to impart necessary awareness \& understanding regarding menstrual hygiene to adolescent girls. The teaching can also be extended to all adolescent girls and to the school students in general who plays a role in influencing the kind of knowledge that girls have regarding menstrual hygiene. Since it has been observed that lack of proper information about health and hygiene, particularly in rural areas, results in complications and confusions, therefore health workers should focus more in rural areas regarding menstrual hygiene along with the urban areas in order to help adolescent girls to improve their knowledge regarding menstrual hygiene.

\section{Nursing Research:}

The findings of this study serve as basis for professional nurse to conduct further studies on menstrual hygiene. The present study will open the new avenues for explaining many other issues in the schools by nurse researchers. This is not only to find out knowledge of adolescent girls for the critical years but also to understand and address the problem faced by rural adolescent girls due to lack of health services. This would also enable to understand a comparison about the knowledge of rural and urban adolescent girls regarding menstrual hygiene and plug in the gaps. Such knowledge would in turn enables nurses to be more sensitive to the varied needs of the adolescent females and render services to their circumstances.

\section{Nursing Administration:}

The findings of the present study will assist nurses in administrative post in the community and hospital to educate adolescent girls about the menstrual hygiene. The nursing personal should be prepared to take up leadership roles in imparting knowledge to adolescent girls about menstrual hygiene.

\section{Recommendation:}

A similar study on large size sample can be conducted to generalize the findings. A comparative study can be undertaken in different community areas. The similar study can also be conducted among rural and urban areas. A study may be undertaken with control group. A similar study can be conducted using standard teaching module for assessing the knowledge of teenage girls about menstrual hygiene.

\section{Funding -}

Present study has been conducted without any grant from any funding agency in public, private, or nonprofit sectors.

\section{Availability for data and materials -}

Not applicable

Gallery Proof copy

\section{Declaration-}


Due approval and consent from participants were received.

The study was approved from institutional ethics committee, Principal, Santosh Nursing College, Ghaziabad (UP)

\section{Competing interest-}

There exist no potential conflict of interest.

\section{Bibliography-}

1. Terri kyle. "Essentials of Paediatric Nursing. South Asian edition. 2008.wolters klumber publishers. India private limited. Page no. 72, 184.

2. Dawn C.S. "Textbook of obstetrics, Neonatology and Reproductive and child health education. Revised $16^{\text {th }}$ edition. 2004. Dawn books, Kolkata. page no. 27.

3. Hygiene expert, "What is Personal hygiene? (UK). Cited on 4.04.2019 available from www.hygiene expert.co.uk/what is hygiene.html.
4. K Devi drakshayani, et al. "A study on menstrual hygiene among rural adolescent girls". Indian Journal of Medical Sciences.1994 June. revised 2004 Nov. 48:139-43.

5. A Dasgupta, M Sarka, Menstrual, "Menstrual Hygiene." How hygiene is the adolescent girl? 2008(33), (2):72-80

6. A Copy of the report: Is menstrual hygiene and management an issue for adolescent school girls. 2008: 91-107.

7. Dr. Prasad Adhikari. P. A study on knowledge and practice among adolescent girls. 2007. (5) (3) (19): 382-386.

8. El-Gilany, et al. menstrual hygiene among adolescent school girls in Mansoura Egypt," 2004 (13) (26):146-152

9. Get out of negative head space. Cited on 5.04.2019 katie Brick well. http://www:youtub.com.

10. Mandal, Dhungel. S." Menstruation in girls and adolescent" 2006, (7) (2): 450-455. 